\title{
Ciudadanía y revolución mexicana en Chiapas: $1909-1939^{1}$
}

\author{
Ramón Raymundo Reséndiz García*
}

\author{
Nivel: Ponencia \\ Fecha de recepción: 20 de julio de 2011 \\ Fecha de aprobación: 12 de agosto de 2011
}

\begin{abstract}
Resumen
El núcleo de interés es la formación de la ciudadanía en el estado de Chiapas durante la Revolución Mexicana (1910-1940). Se analiza la situación de la ciudadanía durante el periodo próximo al estallido revolucionario -porfiriato tardío-, sus características y dinámica en el marco de los acuerdos y tensiones entre el nivel federal y estatal gubernamental, así como entre los grupos oligárquicos que se disputan el poder político en la entidad. Posteriormente se detiene en tres periodos de la formación de la ciudadanía en la entidad en el contexto de la Revolución Mexicana. En cada periodo se destacan los vínculos entre lo nacional y lo local, entre la federación y la entidad. También se atiende a la configuración y disputa política interna. Tales factores serán determinantes y formarán parte de un proceso tenso y conflictivo cuyo resultado será una frágil y desigual ciudadanía.

Palabras clave: Ciudadanía, Estado, Chiapas.
\end{abstract}

\begin{abstract}
The main interest is the formation of citizenship in the state of Chiapas during the Mexican Revolution (1910-1940). It examines the status of citizenship during the period close to the outbreak of revolution -delayed Porfiriato-its characteristics and dynamics in the framework of agreements and tensions between the federal and state governments, and also between the oligarchic groups vying for political power in the society. Then, the article makes a point of reflection at three periods of the formation of citizenship in the context of the Mexican Revolution. In each period, the author highlights the links between national and local aspects, and between the federation and the state matters. He also addresses the configuration and internal political dispute. Such factors will be decisive and will be part of a tense and conflictive process that will result in a fragile and unequal citizenship.
\end{abstract}

Keywords: Citizenship, State, Chiapas.

1 Una versión de la presente ponencia, bajo el nombre "La Revolución Mexicana y la construcción de la ciudadanía en Chiapas. 1909-1939", fue presentada en el marco del Congreso Nacional Estado-Nación en México: Independencia y Revolución celebrado del 26 al 30 de abril de 2010 en Tuxtla Gutiérrez, Chiapas, México.

* Doctor en Ciencias Sociales con especialidad en Sociología por El Colegio de México. Facultad de Estudio Superiores Acatlán y Facultad de Ciencias Políticas y Sociales de la Universidad Nacional Autónoma de México, yolot12002@hotmail.com 


\section{Introducción}

Toda revolución alienta una vocación de refundación social plena, pretende subvertir el orden existente y abrir horizontes de futuro que apuntan a una nueva época distanciada radicalmente del antiguo régimen que pretende abolir. No siempre se cumple esa pretensión, a menudo se crea más bien cierta impresión de cambio o de refundación dado que en la realidad coexisten procesos de cambio y de continuidad, de permanencia y de transformación.

La Revolución Mexicana construyó un imaginario de transformación social cuyos componentes más emblemáticos han sido el reparto agrario, la educación, la legislación laboral, entre otros. Ellos pueden reexaminarse a la luz del tema de la ciudadanía, un componente de ese imaginario de transformación que no siempre ha recibido la atención y la importancia que merece.

La construcción de la ciudadanía es el proceso sustantivo que acompaña la construcción del Estado y de la nación. Estado y nación son impensables sin la existencia de ciudadanos. El clásico estudio de Thomas Marshall (1997) sobre el tema de la ciudadanía estableció tres componentes que se han convertido en sus elementos canónicos, a saber: ciudadanía civil, política y social. La primera alude a los derechos fundamentales imprescindibles para la libertad individual; la segunda al conjunto de derechos que le permiten a los individuos participar en el ejercicio del poder político ya sea como miembros o electores de los órganos de autoridad política; el tercero apunta al derecho a participar del patrimonio social y de un mínimo de bienestar económico.

El proceso de constitución de la ciudadanía posee una escala propia de carácter nacional, sin embargo asume expresiones específicas perceptibles a nivel de escalas menores como las locales o estatales. El nivel agregado de la nación no siempre permite advertir las diferencias, las singularidades que asumen procesos como el de la construcción de la ciudadanía, el de la articulación 
de poderes, la formación de los sistemas políticos y la penetración y forma en que se experimenta y realizan procesos de cambio como la revolución misma.

La Constitución Federal de los Estados Unidos Mexicanos de 1857 estableció un conjunto de libertades que favorecieron la construcción de la ciudadanía civil ya que proclamó la libre manifestación de las ideas y la inviolable libertad de escribir y publicar, según establecen sus artículos 6 y 7. La libertad para abrazar la profesión, industria o trabajo acompañó la prohibición expresa de que nadie podía ser obligado a prestar trabajos personales sin pleno consentimiento y justa retribución, según indican los artículos 4 y 5, formando con ello un núcleo de libertad económica que resulta imprescindible para fortalecer la esfera civil de la ciudadanía.

El derecho de asociarse o reunirse pacíficamente con cualquier propósito lícito se reconoció en el artículo noveno, el que reservó a los ciudadanos de la República el derecho de hacerlo "para tomar parte de los asuntos políticos del país". La ciudadanía política decimonónica corresponde a los mexicanos que teniendo un modo honesto de vivir han cumplido 18 años si están casados o 21 si no lo son. La esfera de sus derechos incluye el votar en las elecciones populares y poder ser votado en todos los cargos de elección popular; tomar las armas en el ejército y en la guardia nacional para la defensa de la República, y ejercer en toda clase de negocios el derecho de petición.

Pese al carácter universal de la ciudadanía política, en los hechos operó más como el privilegio de una minoría masculina selecta que contaba con el tiempo, los recursos y la disposición para ejercerla, de modo que los derechos políticos existían, aunque como apunta el mismo Marshall para el caso inglés que analiza, eran defectuosos en su distribución.

En el caso de los derechos civiles ocurría algo similar, pues la base de las libertades civiles es el derecho a la justicia, vale decir el derecho a hacer valer los derechos individuales en condiciones 
de igualdad frente a otros. La ausencia de esas condiciones de igualdad en los hechos más que en los derechos constituyó una barrera de desigualdad que persistió durante el siglo XIX y lo trascendió; recordemos que el magonismo liberal señalaba que los conocimientos que exigían ciertos procedimientos jurídicos como el juicio de amparo, lo hacían inalcanzable para la mayoría de los mexicanos. "La justicia con trabas no es justicia”, advertía el programa del Partido Liberal Mexicano en 1906.

Barreras de desigualdad, defecto de distribución, se advierten a escala nacional. Sin embargo, a nivel de entidades como Chiapas parece plenamente justificada la expresión ficción jurídica, acuñada por Francisco Xavier Guerra, es decir: el pleno desencuentro entre las disposiciones jurídicas y la realidad social, política, económica, en nuestro caso ciudadana.

\section{Ciudadanía restringida y confrontación oligárquica: 1893-1914}

Sistema de enganche, retención forzada, sistema de servidumbre, castigos corporales, dan cuenta de la ficción jurídica y ciudadana. Fincas y monterías constituyen espacios donde se construyen relaciones de explotación y dominio, de plena desigualdad en los derechos económicos, sociales y políticos que contradice y nulifica las libertades económicas, civiles y políticas establecidas por la Constitución de 1857. Hacheros, sirvientes, peones de la sierra, indígenas en general, de Chiapas y el sureste mexicano, forman en los hechos una suerte de legión no ciudadana, pues, en ellos no adquieren forma las libertades, obligaciones y derechos ciudadanos. Ellos no constituyen parte de aquella comunidad basada en el estatus de ciudadanía, como tampoco formarán parte las mujeres, pues la ciudadanía en Chiapas y en México será exclusivamente masculina hasta bien entrado el siglo veinte.

El sistema de servidumbre en Chiapas resulta de interés no solamente porque permite reflexionar sobre los límites reales y 
extremos de la ciudadanía en México, sino también porque su existencia es impensable sin la presencia de un discurso legitimador fundado en la desigualdad en derechos, es decir: en el supuesto contrario sobre el cual se funda teórica y políticamente la ciudadanía, pues ella consiste en una forma de estatus que se otorga a los que son miembros plenos de una comunidad y que al compartir los mismos derechos y obligaciones conforman una comunidad de iguales, no obstante que en otras esferas como la económica existan desigualdades como las de clase.

La desigualdad entre razas, sus desiguales aptitudes y por ello desiguales derechos, forman parte del imaginario racista para el cual forzar el trabajo de individuos considerados indolentes constituye un mérito civilizatorio, tal es el núcleo del racismo porfirista que se generó en Chiapas y que, de acuerdo a Armando Bartra (2001), tendrá en el alemán Otto Peus uno de sus teóricos más importantes.

En la Constitución estatal de 1893, es notable la ausencia del tema de la ciudadanía civil, la idea de una comunidad de iguales basada en libertades y derechos compartidos no está presente a pesar de que fue impulsada por Emilio Rabasa, gobernador y cabeza visible de la oligarquía modernizadora chiapaneca.

El asunto de la desigualdad será abordado explícitamente por el Congreso Estatal en la Ley de Sirvientes de 1912, en virtud de la cual se legaliza la relación de servidumbre mediante deudas, es decir el mecanismo de explotación y control oligárquico, pero también resulta visible el soporte ideológico en virtud del cual moralmente se pretende justificar la validez de esa relación, la supuesta minusvalía del sirviente.

La constitución estatal refleja fielmente la definición federal de ciudadanía política, consagra el sufragio popular universal masculino, no secreto en la primera vuelta e indirecto en primer grado a efecto de renovar los poderes estatales con excepción de los ayuntamientos. 
Votar en las elecciones para cargos públicos, desempeñar cargos de elección popular e inscribirse en los registros de la guardia nacional constituyen obligaciones ciudadanas de acuerdo a la Ley Orgánica Electoral del estado de Chiapas de 1909. Sus derechos consisten en elegir y ser electos en cargos públicos de elección, asociarse en asuntos públicos estatales y tomar las armas de la guardia nacional para la defensa del Estado.

Los electores secundarios del sistema electoral chiapaneco constituyen una ciudadanía minoritaria que a juzgar por las disputadas y controvertidas elecciones de 1911 difícilmente pudo haber llegado a los seiscientos cincuenta ciudadanos. En sus manos se encontraba la elección de gobernador, diputados (12) y magistrados de justicia; se realizaba mediante un Colegio Electoral de base departamental a través de voto directo y secreto, a diferencia de las elecciones primarias.

El congreso local será la máxima autoridad electoral pues asumirá las funciones de colegio electoral y, en cuanto tal, será el responsable de computar los votos para gobernador y magistrados, y declarar candidatos ganadores por mayoría de votos. La ausencia de una mayoría absoluta convertirá al congreso en elector pleno, pues, a través de escrutinio secreto y por cédulas, tendrá la facultad de decidir al ganador entre aquellos candidatos que hubieran obtenido la mayoría relativa.

La función electoral del congreso local asumirá gran importancia política y se expresará intensamente en el periodo 1910-1914, durante el cual designaron y eligieron gobernadores interinos, substitutos y constitucionales en un contexto político marcado por las disputas entre las fracciones oligárquicas chiapanecas y el quiebre del régimen porfirista.

El saldo de los conflictos entre la oligarquía modernizadora o tuxtleca y la tradicional o san cristobalense será favorable para la primera durante los primeros años del siglo $\mathrm{XX}$, los del porfiriato tardío: 1. Habían consolidado a Tuxtla como capital del Estado a pesar del reclamo reiterado de la oligarquía tradicional por res- 
tituirle a San Cristóbal dicho carácter; 2. Mantenían el control de los principales espacios de poder, empezando por el ejecutivo local, y desde ellos; 3. Emprendieron un proceso de transformación económica signado por el apoyo a la agricultura comercial de exportación y la incorporación de capital extranjero.

Cada uno de esos logros tuxtlecos significó desplazar o debilitar a la oligarquía tradicional que reclamaba al gobierno estatal, lo que ellos llamaban: situación de marginación y abandono del cual era objeto San Cristóbal de las Casas, y cuyas razones se encuentran en la creciente centralización política, en el desplazamiento regional de los ejes económicos, de los patrones y circuitos comerciales de la entidad a favor de Tuxtla, cuya oligarquía mantuvo la dirección política y económica de la entidad, subordinando a la oligarquía tradicional a una modernización económica que no prescindió del sistema de servidumbre. Y, con ello, mantuvo intacto el fundamento del dominio y control oligárquico, lo cual permitiría la resistencia y posterior ofensiva de la fracción San Cristóbal.

Entre 1910 y 1914 se procesó nacionalmente el colapso del porfiriato y la emergencia de los ejércitos revolucionarios que le disputaron el monopolio de la violencia legítima. Ello abre en Chiapas una serie de coyunturas que permitirán la abierta confrontación entre sus fracciones oligárquicas. Sus escenarios son diversos y van de los espacios electorales a la lucha armada.

La primera disputa es por la designación del gobernador interino tras la renuncia de Ramón Rabasa en 1911. Trejo, Gordillo León, Rueda y Rovelo son gobernadores entre mayo y agosto de ese año, su fragilidad y fugacidad expresa los conflictos entre las fracciones oligárquicas chiapanecas que intentan hacerse del poder político y aprovechar en su favor la intervención de las fracciones maderistas que presionan también la decisión del congreso local.

La segunda disputa será por la elección de diputados del congreso local, cuyo saldo será favorable al grupo Tuxtla que ganará 
siete de los trece departamentos en disputa, cuatro serán para el grupo San Cristóbal ${ }^{2}$, mientras Pichucalco y Chiapa serán ganados por candidatos de filiación independiente, aunque en el proceso de calificación sus elecciones serán declaradas nulas.

Con un congreso hegemonizado por los tuxtlecos la reacción san cristobalense será el levantamiento armado apoyado en una frágil e inusitada alianza con los chamulas. El 14 de septiembre de 1911 desconocen la legalidad del proceso electoral y al gobernador, a quien acusan de haberlo violentado. La fracción tuxtleca obtendrá el apoyo político y militar del gobierno federal, lo cual será determinante para obligar al grupo San Cristóbal a negociar el cese de hostilidades a casi un mes de iniciado el conflicto.

Reconocimiento del gobierno de Rovelo, desarme de las fracciones en pugna, amnistía general y elecciones limpias serán los acuerdos que sellarán el armisticio. Los conflictos emergerán nuevamente ante la elección del gobernador de la entidad y la calificación del proceso electoral, cuya falta de transparencia parecía alimentar una nueva rebelión. El nombramiento de Flavio Guillén como gobernador interino en sustitución de Reinaldo Gordillo, declarado Gobernador Constitucional del Estado apenas un mes antes, será la manera de establecer una precaria estabilidad política, que será mantenida hasta julio de 1913, cuando Victoriano Huerta militariza los gobiernos estatales, incluido el de Chiapas, que quedará en manos de Bernardo A.Z. Palafox hasta agosto de 1914.

Esta coyuntura de abierta confrontación oligárquica muestra la fragilidad del sistema electoral chiapaneco y las consecuencias de la ficción electoral del antiguo régimen. La ausencia de un órgano electoral autónomo que garantice la transparencia, equidad

2 Los siete son Comitán, Mariscal, Mescalapa, Palenque, Soconusco, Tonalá y Tuxtla Gutiérrez. Chilón, Las Casas, La Libertad y Simojovel serán los departamentos ganados por el grupo San Cristóbal. 
y certidumbre del proceso electoral, hace del congreso local el escenario de las disputas entre las distintas fracciones que contendieron electoralmente. El núcleo de confrontación es la calificación de las elecciones, particularmente las de gobernador. La debilidad del sistema electoral y la ausencia de acuerdos locales permiten que el ejecutivo federal sea el factor de contrapeso. Su intervención será crucial para el nombramiento de Flavio Guillén como gobernador interino, un mes después de haber declarado a Reinaldo Gordillo León como Gobernador Constitucional del Estado, en medio de la inconformidad de la oligarquía de las tierras altas.

\section{La rebelión oligárquica y la ciudadanía social: 1914-1919}

A la derrota nacional del huertismo correspondió el fin del gobierno militar de Palafox en 1914 y la recuperación transitoria del gobierno estatal por parte de la oligarquía tuxtleca a través de José Inés Cano, nombrado, otra vez el Congreso como elector, por la décima octava legislatura estatal. Sin embargo, la presencia de la División 21 del ejército constitucionalista en Chiapas, al mando del general José Agustín Castro, selló el inicio de una nueva etapa política en la entidad.

Con la misión de licenciar las tropas federales y asumir el control de la entidad, Castro disolvió los poderes locales, militarizó la estructura administrativa estatal y asumió el gobierno del estado centralizando las atribuciones de los poderes disueltos. Sin embargo, para el gobernador militar su misión era de reforma y liberación, excedía la simple ocupación. Ciudadanía, libertad, saber, igualdad, eran los grandes objetivos de la Revolución, que intentaría realizar en la entidad a través de una amplia labor legislativa.

El 13 de octubre de 1914 Castro promulgó la Ley de Obreros, en virtud de la cual se decreta la inexistencia de sirvientes en 
la entidad, la abolición de deudas y la prohibición explícita de crear otras nuevas y arraigar a los trabajadores por medios coactivos. En contraparte estableció la relación salarial como norma contractual; un esquema de salarios mínimos por actividad y región (departamentos), y dispuso una jornada máxima de trabajo de ocho horas en el caso de la minería y diez en el resto de las actividades. Patrones y finqueros, según la ley, deberán otorgar asistencia médica, instrucción y seguro por accidentes laborales a sus trabajadores.

En su conjunto estas medidas apuntan a la formación jurídica de los espacios de libertad económica y a la constitución de un mínimo de bienestar social. En el primer caso aluden a la ciudadanía civil, en el segundo a la ciudadanía social. Circunstancia paradójica, si tomamos en cuenta que la ciudadanía política en la entidad ha sido suprimida por la ocupación militar y la disolución de los poderes locales.

Ocupada la entidad, disueltos los poderes estatales, confiscados sus derechos políticos y frente a una legislación que estableció derechos civiles y sociales incompatibles con la servidumbre, en tanto sustento económico y social de la riqueza, prestigio y dominio patrimonial oligárquico, los finqueros chiapanecos percibirían con absoluta claridad el significado de dicha legislación. Su respuesta será igualmente clara. El Acta de Canguí del 2 de diciembre de 1914, formaliza la resistencia armada y constituye el núcleo político ideológico capaz de agrupar los intereses de las distintas fracciones oligárquicas confrontadas en el pasado y ahora crecientemente unificadas bajo el liderazgo de Tiburcio Fernández Ruiz, al cual se sumarán las fuerzas de Alberto Pineda en 1916, quien encabezará la rebelión armada en la región de los Altos.

El acta rebelde legitima la respuesta armada ante lo que consideran invasión de un grupo armado que ha vulnerado las "instituciones políticas, base de nuestra soberanía" [...] "atacando lo que de más sagrado tiene el hombre, el hogar" (Serrano: 1923, 
13). Propiedad territorial y relaciones de servidumbre son componentes básicos de las relaciones de dominio y explotación, en función de ellos se estructura familia, alianzas y lealtades políticas.

Tierra y servidumbre simbolizan plenamente el hogar de la oligarquía; constituyen a su vez el sustento de la angosta base social de la cual forman parte exclusiva los propietarios de la tierra; son el soporte del círculo cerrado de funcionarios gubernamentales reclutados en función de parentesco, amistades y lealtades. Tierra y servidumbre son los activos materiales que sustentan el ejercicio de una dominación coercitiva y, por ello, oligárquica (Ansaldi, 2008, 2), que excluye a la mayoría de la sociedad chiapaneca, cuya minoría dominante se considera superior al resto de la sociedad. Es esa minoría, la comunidad política activa del Estado, la que se levantará en armas y la que mantendrá la dirección política de la misma, a pesar de la inclusión de otros sectores sociales. Recordemos que, de acuerdo a la Ley Orgánica Electoral del Estado de Chiapas de 1909, tomar las armas de la guardia nacional para la defensa del estado es un derecho reservado a los ciudadanos chiapanecos. Es el núcleo ciudadano minoritario el que se levanta en armas en contra de la presencia militar carrancista en el estado.

Blas Corral sustituyó a Castro en el gobierno militar de la entidad, el esfuerzo legislativo de ambos realizado entre 1914 y 1916 amplió y precisó los derechos constitutivos de la ciudadanía social. Entre ellos los derechos laborales y de salud, aunque discursivamente a la educación le correspondió un lugar especial como medio para desterrar la ignorancia y el fanatismo, la explotación y la servidumbre.

La Ley de Instrucción Pública de Chiapas, expedida durante la administración de Blas Corral, estableció la educación pública gratuita, laica y obligatoria en su nivel primario, orientada a formar el recto criterio, las virtudes sociales y "el sentimiento de civismo" como soporte de la democracia y la república. Por otra 
parte, prohibió la contratación de menores de 14 años sin que hubieran terminado la primaria y estableció la gratuidad de la educación impartida por el Estado en primaria, secundaria, especial y profesional.

El arribo de Pablo Villanueva a la gubernatura de la entidad en sustitución de Blas Corral, en 1916, significó un cambio político sustancial. El nuevo gobernador asumió una política conciliatoria, incluyendo en su gobierno a familiares o personajes cercanos a los rebeldes. La estrategia será poco eficaz pues la oligarquía en armas condicionó el cese de las hostilidades al retiro de las tropas carrancistas de la entidad y la elección de un gobierno civil compuesto por nativos del Estado. Se trataba de las condiciones básicas para restablecer el dominio oligárquico en la entidad, de la cual la ciudadanía política restringida y excluyente era sin duda el mecanismo político clave.

Sin posibilidad de acuerdo entre los combatientes, sin capacidad de unos y otros para imponerse militarmente sobre su contendiente, unos controlando primordialmente las zonas rurales, otros las urbanas, se estableció una suerte de equilibrio que se romperá a favor de los finqueros en 1920 en virtud del conflicto entre Carranza y Obregón y el triunfo de los rebeldes de Agua Prieta, con los cuales se aliaron los rebeldes chiapanecos.

Previo al rompimiento del equilibrio político militar en la entidad, merece destacarse la convocatoria para las elecciones de diputados al Congreso Constituyente, a celebrarse en octubre de 1916, cuyo decreto expedido por Carranza y reexpedido por Villanueva en la entidad estableció por vez primera el sufragio directo que alimentó la ciudadanía política del siglo veinte surgida de la Revolución Mexicana.

La Ley Reglamentaria del Trabajo expedida en 1918 reguló provisionalmente el artículo 123 de la Constitución de 1917 y recuperó la legislación laboral expedida por los gobiernos carrancistas en Chiapas. Presenta como novedades en la entidad el reconocimiento del derecho de obreros y patrones de "coali- 
garse en defensa de sus respectivos intereses" (31), según estableció su artículo 175, mientras el 188 reconoció como derecho "económico social, las huelgas y paros". Ambos artículos son parte de la cobertura normativa que permitió le emergencia de los sindicatos en Chiapas. La Ley en su conjunto forma parte de los esfuerzos por consolidar una legislación laboral, un conjunto de derechos sociales que den soporte a la ciudadanía social en la entidad.

\section{La rebelión hecha gobierno. Tensiones y disputas: 1920-1936}

El triunfo de la Rebelión de Agua Prieta a nivel nacional significó el triunfo a nivel estatal de los finqueros chiapanecos y el restablecimiento de los poderes locales. Al igual que Obregón, Tiburcio Fernández transitó el camino de la legalidad electoral para obtener la gubernatura del Estado. Al restablecimiento legal del ejecutivo le acompañó el del congreso local que proclamó, el 28 de enero de 1921, la nueva Constitución Política del Estado de Chiapas, cuya orientación contrasta con el contenido social de la Constitución Política de los Estados Unidos Mexicanos de 1917. Reorganización y funcionamiento de los poderes locales, sus ámbitos de competencia, configuración y formas de renovación constituyen los puntos de interés de la nueva constitución de la oligarquía triunfante.

En continuidad con la constitución de 1893, la de 1921 restableció la división de poderes y la independencia entre los mismos. Sus novedades son: el reconocimiento de los derechos civiles, particularmente la igualdad jurídica que se concede a todos los habitantes de la entidad; la ampliación del número de diputados a 16; la elección del poder judicial por el congreso estatal; el incremento de las atribuciones del ejecutivo y la división político-administrativa de la entidad a través de los municipios, sin la interferencia de las jefaturas políticas. 
La ciudadanía política es virtualmente la misma de la constitución anterior y alude a los nacidos en territorio chiapaneco, de padres mexicanos, con 18 años siendo casados y 21 si son solteros, así como a los ciudadanos mexicanos con un año de residencia en la entidad.

Toda elección será directa y popular según la nueva constitución, aunque no secreta. Combinatoria que nos muestra las tensiones entre cambio y continuidad que caracterizan al nuevo gobierno de la antigua oligarquía que parece no encontrarle un lugar propio al sufragio que aparece en la nueva constitución formando parte de un grupo heterogéneo de disposiciones generales.

Los derechos sociales tampoco encuentran un lugar en la Constitución: educación, reformas agrarias y laborales son parte de sus disposiciones generales. Restablecer las instituciones de poder local es lo fundamental, curiosamente en una perspectiva más próxima al carrancismo que al reformismo social.

La ausencia de un espacio propio para los derechos sociales constitutivos de la ciudadanía social se complementó con un conjunto de decisiones de política que delinean un perfil conservador en el gobierno de Ruiz. Por una parte, una Ley de Latifundios que virtualmente permitió legalizar las grandes propiedades mediante su fraccionamiento y traspaso a familiares y prestanombres de sus propietarios. Por la otra, el establecimiento de una Comisión Local Agraria que promovió el reparto de tierras nacionales, salvaguardando así las pertenecientes a la oligarquía.

La intervención coyuntural del gobierno estatal en materia laboral solamente en caso de conflictos, en materia de salud ante contingencias sanitarias e intermitente en el caso educativo, contrasta con la activa participación gubernamental en el caso de las políticas destinadas a la recuperación y reorganización económica. Una intensa labor legislativa destinada a reducir impuestos a la exportación de ganado, la elaboración de un nuevo catastro para fincas rústicas, la condonación de impuestos para las fincas ubicadas en zonas de conflicto, entre otras. 
La Ley Orgánica Electoral contemporánea de la Constitución de 1921, establece la renovación del Poder Legislativo por mitad cada dos años; del Ejecutivo cada cuatro años y los ayuntamientos, delegados municipales y alcaldes, cada año mediante elección directa.

El municipio es uno de los protagonistas emergentes en materia electoral. Las secciones electorales, la elaboración del padrón electoral, la ubicación de las casillas electorales tendrán una base y participación municipal. Esa descentralización a menudo se traducirá en el control de los caciques locales del proceso electoral y será una de las fuentes de tensiones y conflictos electorales al menos entre 1920 y 1940.

El establecimiento de un sistema de colegios electorales municipal, distrital y estatal fue la respuesta organizativa e institucional a la ampliación del sufragio en virtud de su carácter popular y directo. La reglamentación y referencia explícita a los partidos políticos como protagonistas del proceso electoral será parte de las innovaciones en materia de legislación electoral. Para ser reconocido y formar parte de la contienda electoral un partido requiere haber sido fundado por una Asamblea Constitutiva de al menos 25 ciudadanos, contar con mesa directiva, un programa de gobierno y haber protocolizado su acta constitutiva, según establece el artículo 31 de la Ley Orgánica Electoral del Estado de Chiapas.

En 1925, con Carlos Vidal como gobernador del estado, la Nueva Ley electoral reforzó los controles sobre los partidos e incrementó los requerimientos para su registro. La exigencia consistirá en inscribirse ante la Secretaría General de Gobierno del Estado y ante cada ayuntamiento de las cabeceras distritales. Se incrementó al doble el mínimo de ciudadanos presentes en su asamblea constitutiva, que pasó a cincuenta, y se prohibió explícitamente que su propósito y denominación fuera religiosa.

Dos recursos de control de las autoridades locales son particularmente importantes en materia electoral. En primer lugar 
la improcedencia e invalidez de las protestas partidarias que se realicen grupalmente y no a través de sus representantes partidarios y por escrito. En segundo lugar, la facultad del Congreso de suspender a su juicio la toma de posesión de aquellos ayuntamientos o delegaciones sobre los cuales haya recibido queja, nombrando en su lugar un Consejo Municipal tal como lo permite la constitución local. En un caso es clara la intención de desactivar cualquier protesta colectiva, en el otro la posibilidad de remoción discrecional de presidentes municipales, regidores, delegados y ayuntamientos en su conjunto. Ambas medidas constituyen la respuesta a las conflictivas elecciones locales de 1924, mediante las cuales Vidal accede al gobierno del Estado.

El control sobre el proceso electoral y los partidos que caracterizó la administración de Carlos A. Vidal se complementó con una orientación de reforma social sustentada políticamente en el Partido Socialista de Chiapas y la Confederación Socialista de Trabajadores de Chiapas.

A juzgar por la ausencia de organizaciones obreras, sindicales y partidistas populares en los valles centrales, en la región de los altos y, en general, en la mayoría del estado, con excepción del la región del Soconusco, el impacto de la legislación carrancista había cambiado muy poco la situación política y social de la entidad. La moderna agricultura de exportación del Soconusco, la coexistencia de relaciones salariales y formas de explotación tradicional, sumado al amplio espectro cultural de los trabajadores son factores que permiten explicar el excepcional surgimiento en 1920 del Partido Socialista del Soconusco (posteriormente Partido Socialista Chiapaneco), que fue convertido en partido oficial durante el vidalismo.

Entre 1924 y 1928, se favoreció la educación elemental y la organización sindical de los trabajadores. Por su parte, el Congreso legisla a favor de una ciudadanía social que siempre parece precaria ante las enormes desigualdades. Expedición de la Ley Reglamentaria de la Conciliación y Arbitraje entre patrones y tra- 
bajadores en 1926, reglamentación de la contratación de peones y la declaratoria de la validez de la Ley Reglamentaria del Trabajo expedida en 1918, son parte del esfuerzo destinado a regular los conflictos obrero-patronales y evitar las prácticas de explotación servil y abusos por parte de finqueros y enganchadores.

El gobierno de Vidal y el vidalismo serán abatidos por el gobierno central en su confrontación contra la revuelta del general Francisco R. Serrano, de quien el gobernador chiapaneco fue director en su infortunada campaña política. Raymundo Enríquez, nuevo gobernador a partir de 1928, enfatizará el tema del reparto agrario como núcleo de la alianza entre gobierno y sectores populares. Las 171.886 hectáreas repartidas, más que una decisión destinada a favorecer una sólida ciudadanía social, dan cuenta de la importancia del reparto agrario como estrategia para consolidar las bases de apoyo del nuevo gobierno.

Durante la administración de Enríquez se ampliaron los requisitos para la participación de los partidos políticos en las elecciones, a saber: registrarse ante la Secretaría General de Gobierno cuando menos dos meses antes de la fecha de la elección, y constituirse en asamblea no menor de 100 ciudadanos debidamente conocidos en el Estado y en pleno ejercicio de sus derechos. La posibilidad de candidatos independientes constituye una de las novedades más importantes de la Ley Electoral del Estado de Chiapas de enero de 1932.

\section{El cardenismo en Chiapas: el desequilibrio entre ciudadanías: 1936-1939}

Victórico Grajales fue el candidato del $\mathrm{PNR}^{3}$ al gobierno del estado. Hacendado y diputado local accede a la gubernatura estatal

3 Partido Nacional Revolucionario, antecedente del Partido de la Revolución Mexicana (PRM), a su vez predecesor del actual Partido Revolucionario Institucional (PRI) en México. 
en 1932 y encabeza el renovado intento de finqueros y ganaderos por contener las reformas sociales, cuya continuidad y profundidad son altamente dependientes de la voluntad gubernamental, lo que dota a la ciudadanía social de gran fragilidad y escasa densidad institucional, como lo muestra la persistencia de las relaciones de servidumbre a través de mecanismos de retención coactiva de los trabajadores en las fincas como en el caso del baldiaje (Legorreta, 2008).

La defensa de los intereses territoriales oligárquicos mediante el control de la Comisión Local Agraria, cuyos repartos se concentraron en las zonas de colonización, fue la manera de proteger a los finqueros del reparto agrario. Fomento económico, creación de infraestructura, exenciones fiscales y la abierta promoción de las organizaciones de ganaderos serán parte de los recursos gubernamentales destinados a fortalecer a la antigua oligarquía, y contener y limitar la organización y movilización de los sectores populares.

Formación de sindicatos pro-patronales, control de las organizaciones sindicales por parte de finqueros y ganaderos; represión y contención de los sindicatos independientes son parte de una reacción oligárquica que mostró la extrema debilidad de la ciudadanía civil, también la capacidad de las fuerzas locales de confrontarse con el gobierno federal encabezado por Cárdenas, cuyo proyecto de reformas se sustentó en la alianza y movilización de los sectores populares.

Las elecciones para gobernador del Estado en 1936, son el escenario de la confrontación entre cardenistas y grajalistas, los primeros apoyando a Efraín Gutiérrez, los segundos a Samuel León. Al triunfo del candidato cardenista correspondió una reacción violenta del gobernador en funciones contra el gobernador electo. La respuesta presidencial será solicitar al Senado el desconocimiento del gobernador Grajales, quien fue sustituido por Amador Coutiño en espera del arribo de Gutiérrez al gobierno del Estado en diciembre de 1936. 
Cuatro dimensiones de la ciudadanía social parecen relevantes ante el impacto cardenista en la entidad: La política de reparto agrario, la educativa, la indígena y la laboral.

El reparto agrario destaca por su amplitud, pues superó al realizado durante el periodo 1918-1934 -53.748 hectáreas frente a 53. 466-, sin embargo será insuficiente para resolver la demanda de tierra en la entidad, eliminar el control territorial de los finqueros y amortiguar los conflictos derivados por problemas territoriales. La participación del patrimonio social y el derecho a un mínimo de bienestar económico, núcleo de la ciudadanía social, será una realidad solo para una parte de los chiapanecos.

La creación del Departamento de Educación Rural e incorporación Indígena en 1937 -posteriormente denominado Departamento de Protección Indígena-, estableció un cambio importante en la política educativa en tanto asumió como tarea la integración del indígena a la nación, en contraste con la concepción de gobiernos anteriores, como el de Grajales, que lo consideran un obstáculo para la modernización del país (Pombo: 2007). Alfabetización, defensa de los intereses materiales y organizaciones sindicales serán parte de los propósitos declarados.

La formación del Sindicato de Trabajadores Indígenas muestra la articulación del tema indígena y laboral en la entidad. Cobertura y apoyo a los indígenas en su lucha por mejores condiciones laborales y salariales es una parte de las funciones del sindicato, la otra es encapsular corporativamente a sus agremiados neutralizando el control político electoral de los finqueros. Ello significó el apoyo institucional a los componentes laborales de la ciudadanía social a cambio de confiscar la ciudadanía política, el derecho a participar en el ejercicio del poder que supone el derecho de voto. De esa manera se configuró una suerte de desequilibrio entre las dimensiones de la ciudadanía, pues, ideológica y políticamente se privilegió la social en detrimento de la civil y la política, aunque en los hechos la fragilidad y deficiencia en el caso de las tres será crónica y preocupante. 


\section{Conclusión}

Un balance provisional del proceso de constitución de la ciudadanía permite advertir una ciudadanía civil vulnerable, pues, el derecho a hacer valer los derechos de cada uno en condiciones de igualdad ante los demás, constituye más bien una aspiración ante barreras derivadas de la desigual distribución de la riqueza y derechos sociales básicos como la educación.

Los límites a la ciudadanía civil en virtud de la fragilidad de ciertos derechos sociales muestran a su vez la debilidad de la ciudadanía social: una legislación laboral cuya aplicación no siempre es imparcial; un reparto agrario limitado que no logró dotar de patrimonio a la mayoría de los chiapanecos y limitadamente eliminó las condiciones de desigualdad que posibilitaron la servidumbre; una alfabetización que entre 1910 y 1940 apenas redujo en diez puntos porcentuales el analfabetismo, pues, de $86,6 \%$ pasó a $76,2 \%$ en la entidad.

La expansión y consolidación del partido oficial y sus organizaciones corporativas neutralizaron el sufragio como derecho a participar en el ejercicio del poder, particularmente indígenas y campesinos serán vulnerables al control político y electoral en un periodo de incontenible ampliación del sufragio. Frente a los 624 votos en 1910 contrastan los 115.214 sufragios de 1936.

Cien años después de iniciada la Revolución Mexicana en modo alguno puede decirse que el ciclo de construcción de la ciudadanía se ha cumplido en Chiapas y en México. Hacer de su construcción en sus distintas dimensiones clásicas y emergentes, el eje de las acciones ciudadanas, constituye una buena manera de conmemorar el centenario de la Revolución y el bicentenario de la Independencia que, en 2010, celebran los mexicanos. 


\section{Bibliografía}

Ansaldi, Waldo (2008): “Frívola y casquivana, mano de hierro en guante de seda. Una propuesta para conceptualizar el término oligarquía en América Latina", Imago Mundi, Disponible en: http:/ / www.serviciosesenciales.com.ar/articu

Bartra, Armando (2001): “Teoría y práctica del racismo. Plantaciones y monterías en el porfiriato", Ciencias, octubre-marzo, Universidad Nacional Autónoma de México. Redalyc, UAEM. Disponible en: http.redalyc.uaemex.mx

Benjamin, Thomas Luois (1990): El camino a Leviatán, México, Conaculta.

Carbonell, Miguel (2004): Constituciones históricas de México, México, Porrúa-UNAM.

Carbonell, Miguel (1893): Constitución Política del Estado de Chiapas expedida por el H. Congreso del mismo. Tuxtla Gutiérrez, Imprenta del Gobierno del Estado.

Carbonell, Miguel (1921): Constitución Política del Estado de Chiapas. Tuxtla Gutiérrez Imprenta del Gobierno del Estado,

Departamento de Estadística Nacional (1926): Censo General de Habitantes. Estado de Chiapas, México, Talleres Gráficos de la Nación.

Estados Unidos Mexicanos (1943), $6^{\circ}$ Censo de Población. 1940. Chiapas, Dirección General de Estadística.

García de León, Antonio (1981): Resistencia y utopía. Memorial de agravios y crónica de revueltas y profecías acaecidas en la provincia de Chiapas durante los últimos quinientos años de su historia, México, Era.

Guerra, Francisco Javier (1988): México: Del antiguo régimen a la revolución, México, Fondo de Cultura Económica.

Legorreta, Ma. del Carmen (2008): Desafíos de la emancipación indígena. Organización señorial y modernización en Ocosingo Chiapas (1930-1994), México, CEEIICH-UNAM.

(1918): Ley y Reglamento de Instrucción Pública del Estado de Chiapas. Tuxtla Gutiérrez, Imprenta del Gobierno.

(1909): Ley Orgánica Electoral del Estado de Chiapas. Tuxtla Gutiérrez, Imprenta del Gobierno. 
(1911): Ley Orgánica Electoral del Estado de Chiapas. Tuxtla Gutiérrez, Imprenta del Gobierno.

(1924): Ley Orgánica Electoral del Estado de Chiapas. Tuxtla Gutiérrez, Imprenta del Gobierno.

(1939): Ley Electoral Vigente en el Estado de Chiapas. Tuxtla Gutiérrez, Talleres Lino-tipográficos del Gobierno del Estado.

(1918): Ley Reglamentaria del Trabajo. Tuxtla Gutiérrez, Imprenta del Gobierno.

Marshall, Thomas Humprey (1997): Ciudadanía y clase social, en REIS, Madrid, julio-septiembre, Núm. 79.

Paris Pombo, Ma. Dolores (2007): “El indigenismo cardenista y la renovación de la clase política chiapaneca (1936-1940)", Revista Pueblos y Frontera Digital. Disponible en http:/ /www. pueblosyfronteras,unam.mx

(1914): Periódico Oficial del Estado de Chiapas, Núm. 39, 23 de septiembre.

Reséndiz, Ramón (1995): “Cuarta Parte: 1911-1940”, en Carlos Ruiz Abreu (Coord.), Historia del H. Congreso del Estado de Chiapas. Tuxtla Gutiérrez.

Secretaría de la Economía Nacional (1935): Quinto Censo de Población. 1930. Estado de Chiapas, México, Talleres Gráficos de la Nación. 